$\xi=-1$

\title{
Fortunella japonica extract as a reducing agent for green synthesis of silver nanoparticles
}

\author{
Nguyen Phung Anh ${ }^{1}$, Truong Thi Ai Mi ${ }^{1}$, Duong Huynh Thanh Linh ${ }^{1}$, Nguyen Thi Thuy Van ${ }^{1}$, \\ Hoang Tien Cuong ${ }^{1}$, Nguyen Van Minh ${ }^{2}$, Nguyen Tri ${ }^{1} *$ \\ ${ }^{1}$ Institute of Chemical Technology - VAST, 01 Mac Dinh Chi Str., Ho Chi Minh City, Vietnam \\ ${ }^{2}$ Open University Ho Chi Minh City, 97 Vo Van Tan Str., Ho Chi Minh City, Vietnam \\ *Corresponding author E-mail: ntri@ict.vast.vn
}

\begin{abstract}
A rapid way of synthesizing silver nanoparticles (AgNPs) by treating $\mathrm{Ag}^{+}$ions with a green Fortunella Japonica (F.J.) extract as a combined reducing and stabilizing agent was investigated. The reaction solutions were monitored using UV-Vis spectroscopy, the size and shape of crystals were determined by scanning electron microscopy and transmission electron microscopy, the crystalline phases of AgNPs were presented by X-ray diffraction, and the relation of nanoparticles with Fortunella Japonica extract was confirmed using fourier transform infrared spectroscopy. The results indicated that no formation of AgNPs had taken place in the dark during 24 hours at room temperature and $40^{\circ} \mathrm{C}$. Meanwhile, it was found that the rate of AgNPs formation increased rapidly under the sunlight. The effects of the synthesis factors on the AgNPs formation were investigated. The suitable conditions for the synthesis of AgNPs using F.J. extract were determined as follows: F.J. extract was mixed with $\mathrm{AgNO}_{3} 1.75 \mathrm{mM}$ solution with the volume ratio of $3.5 \mathrm{AgNO} 3$ solution/1.5 F.J. Extract, stirred $300 \mathrm{rpm}$ for 150 minutes at $40{ }^{\circ} \mathrm{C}$ under sunlight illumination. At these conditions, AgNPs showed high crystalline structure with the average size of $15.9 \mathrm{~nm}$. The antibacterial activity of silver nanoparticles was determined by agar well diffusion method against $E$. coli and $B$. subtilis bacteria. The green synthesized AgNPs performed high antibacterial activity against both bacteria.
\end{abstract}

Keywords: Fortunella Japonica Extract; Reducing Agent; Green Synthesis; Silver Nanoparticles.

\section{Introduction}

Nanotechnology has been promising as a rapidly developing field with its application in science and technology. Noble metal nanoparticles such as silver, gold and platinum are broadly applied in medicinal applications. Among noble metals, silver nanoparticles (AgNPs) have received enormous attention in various fields such as biomedicine (medical biology) [1], drug delivery [2], water treating [3], agriculture [4], etc. Because of their extraordinary defence against wide range of microorganisms as well as the appearance of drug resistance against commonly used antibiotics [5], AgNPs were applied in biology, living organisms and medicine. Besides, due to their high conductivity [6], AgNPs were also applied in inks, adhesives, electronic devices, pastes, etc.

AgNPs had been synthesized by physio-chemical methods including chemical reduction [7], gamma ray radiation [8], micro emulsion [9], electrochemistry [10], laser ablation [11], hydrothermal method [12], microwave [13] and reduction of photochemical [14]. Although these methods had effective performance, they associated with the limitations like using toxic chemicals, high operational cost and energy needs. Therefore, the development of environmentally friendly processes of NPs synthesisusing no toxic chemicals with low cost has been a big challenge.

The exploit of green chemistry for the synthesis of AgNPs has obtained substantial achievements in the latest years. Considering the advantages, the effective cost and energy efficient, new substitutionfor AgNPs synthesis using microorganisms [15], plant extracts [16] and natural polymers [17] as reducing and capping agents has been emerging really fast. The association of nanotech- nology and green chemistry has unfolded the range of AgNPs synthesis. The publications on green synthesis of AgNPs were investigated [13]. Most of these reviews focused on several plant and microbial sources for the synthesis. In which, plant parts like seeds [18], leaf [19], bark [20], stem [21] and fruit extracts [22] have been effectively used for synthesizing AgNPs.

Fortunella Japonica - a member of the Citrus genus has long been cultivated in Japan, China, and Southeast Asia. In addition to being used in the food industry, it has been used in folk medicine for treating sore throat and coughing. The extracts from Fortunella Japonica fruit and peel have previously been reported to contain various nutrients and components such as ascorbic acid, carotenoids, essential oils, and flavonoids [23]. The previous publications on Fortunella Japonica have provided evidences about abilities to promote health effects and pharmacological activities of Fortunella Japonica extract, including antioxidant activity [24], anti-metabolic disorder [25], and antimicrobial [26]. However, up to now no paper of AgNPs synthesis has been reported using Fortunella Japonica extract as a combined reducing and stabilizing agent.

In this paper, silver nanoparticles by the reduction of $\mathrm{AgNO}_{3}$ solution were synthesized using Fortunella Japonica extract as a combined reducing and stabilizing agent. The effects of the synthesis time, the volume ratio of $\mathrm{AgNO}_{3}$ solution/Fortunella Japonica extract, the stirring rate, the concentration of $\mathrm{AgNO}_{3}$ solution and the forming temperature of AgNPs were assessed. The physicchemical properties of the obtained AgNPs were investigated. The antibacterial of silver nanoparticles was evaluated against E. coli and B. subtilis bacteria by agar well diffusion method. 


\section{Experimental}

\subsection{Materials}

Fortunella Japonica was collected from Ben Tre, Vietnam. After washing and draining, it was squeezed to obtained solution. The solution was centrifuged at $4500 \mathrm{rpm}$ for 30 minutes to remove the residues. After that, the solution was vacuum filtered through 0.22 $\mu \mathrm{m}$ filters to obtain Fortunella Japonica extract (F.J. Extract). The extract was preserved at $4{ }^{\circ} \mathrm{C}$ till further experiments. Silver nitrate $\left(\mathrm{AgNO}_{3},>99.8 \%\right)$ was purchased from Merck.

\subsection{Synthesis of AgNPs}

For testing the synthesis of AgNPs in the dark, $20 \mathrm{~mL}$ of Fortunella Japonica extract was mixed with $30 \mathrm{~mL}$ of $1.0 \mathrm{mM} \mathrm{AgNO}_{3}$ solution and stirred at $300 \mathrm{rpm}$ for 24 hours at $40{ }^{\circ} \mathrm{C}$ and room temperature $\left(27^{\circ} \mathrm{C}\right)$ in the dark. The synthesis process was conducted with $50 \mathrm{~mL}$ sample/batch.

For the experiments under sunlight, AgNPs were also synthesized according to above procedure and illuminated by sunlight. However, the effects of the factors such as $\mathrm{AgNO}_{3}$ concentration, volume ratio of $\mathrm{AgNO}_{3}$ solution/F.J. Extract, stirring rate, synthesis time and temperature on AgNPs synthesis were surveyed.

\subsection{Characterization of synthesized AgNPs}

The concentrations of silver nanoparticles in the solution were determined by UV-Vis spectrophotometer (UV-1800, Shimadzu, Japan) at a scanning speed of 200 to $800 \mathrm{~nm}$ with a resolution of 1 $\mathrm{nm}$. The morphology of AgNPs was characterized by scanning electron microscopy (SEM) on FE-SEM JEOL 7401 instrument, and transmission electron microscopy (TEM) using JEOL JEM 1400 instrument. A drop of AgNPs solution was put on the carbon stub, dried and observed in TEM or SEM. Crystalline phases of prepared AgNPs powder dried at $60{ }^{\circ} \mathrm{C}$ were investigated by $\mathrm{X}-$ ray diffraction (XRD) using Bruker D2 Phaser powder diffractometer. The relation of nanoparticles with F.J. Extract was confirmed using Fourier transform infrared spectroscopy (FT-IR) carried out on a Tensor 27-Bruker spectrophotometer operating in the range of $400-4,000 \mathrm{~cm}^{-1}$ at a resolution of $2 \mathrm{~cm}^{-1}$.

\subsection{Antibacterial activity of AgNPs}

The obtained AgNPs samples have been tested for antibacterial activity with E. coli and B. subtilis by zone of inhibition test [27]. Colonies were planted with the MHA method (Mueller-Hinton Agar), the bacterias then stored in the agar rods at $4{ }^{\circ} \mathrm{C}$. Three colonies were added in the tube contained $5 \mathrm{~mL}$ pasteurized TSB (Trypticase Soy Broth) and statically cultured at $37^{\circ} \mathrm{C}$ in 18 hours. The paper discs were wetted by the solutions and allowed to dry, these dried discs then got put onto the agar. Store all the samples in the refrigerator in 8 hours and finally incubated at $37^{\circ} \mathrm{C}$ in 18 hours. Antibacterial activity was evaluated by measuring the diameter of the zone of inhibition around the agar.

\section{Results and discussion}

\subsection{Effect of sunlight on the synthesis of AgNPs}

UV-Vis spectral analysis of the samples synthesized in the dark (no light) was shown in Fig.1a. The result showed no remarkable difference in the absorbance patterns of the samples in the wavelength range of $400-450 \mathrm{~nm}$. It indicated that no formation of AgNPs had taken place under completely no light during 24 hours at room temperature. Meanwhile, it was found that the rate of formation of AgNPs increased with the presence of direct sunlight after 30 minutes as shown in Fig.1b, the band indicating AgNPs in the solution in the range of $400-450 \mathrm{~nm}$ was observed. This can be explained that the presence of greater number of photons of certain wavelength in sunlight promoted the reducing action, thus, promoting the AgNPs formation. According to Cumar et al [28], AgNPs formation under sunlight was occurred with four main steps: i) The first step is the photo-activation including the photosensitization of polyphenolic compound (flavonoid) present in extract. As soon as the reaction mixture exposed to sunlight the flavonoid molecule absorbed the photons of energy and got excited. The second step involves the donation of the electrons by debonding of $\mathrm{O}-\mathrm{H}$ group of the excited molecules for the reduction of $\mathrm{Ag}^{+}$to $\mathrm{Ag}^{\circ}$, which put substantial evidence after the photoinduced synthesis of AgNPs. The third step involves the nucleation of $\mathrm{Ag}^{\circ}$ atoms to form nanoclusters, and the fourth step involves the simultaneous growth of the nanoparticles wherein; the nanoclusters nucleated to form the nanoparticles. Further, the protein molecule present in extract is believed to act as a capping agent and stabilized it. This prediction can be evident from the FTIR spectra showing the involvement of $-\mathrm{OH}$ and $-\mathrm{NH}_{2}$ groups in the synthesis and stabilization of AgNPs. The formation of nanoparticles under direct sunlight is described by equations as follows:

$$
\begin{aligned}
& \mathrm{Ag}^{+}+\mathrm{H}_{2} \mathrm{O} \stackrel{h v}{\longrightarrow} \mathrm{Ag}^{\circ}+\mathrm{H}^{+}+\mathrm{HO}^{*} \\
& \mathrm{Ag}^{+}+\mathrm{RCH}_{2} \mathrm{OH} \stackrel{h v}{\longrightarrow} \mathrm{Ag}^{\circ}+\mathrm{H}^{+}+\mathrm{RC}^{*} \mathrm{HOH} \\
& \mathrm{Ag}^{+}+\mathrm{RC}^{*} \mathrm{HOH} \stackrel{h v}{\longrightarrow} \mathrm{Ag}^{\circ}+\mathrm{H}^{+}+\mathrm{RCHO}
\end{aligned}
$$

$\mathrm{nAg}^{\circ} \longrightarrow \mathrm{AgNPs}$

So, the synthesis under direct sunlight was chosen to investigate the effects of other factors on AgNPs formation.

(A)

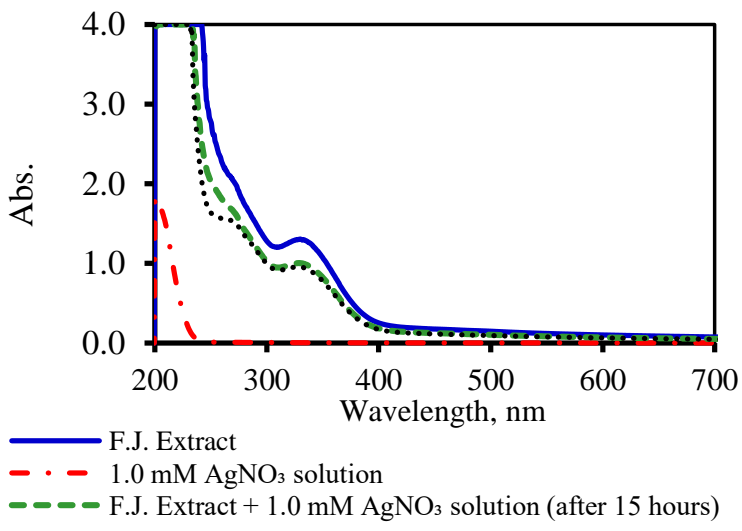

(B)

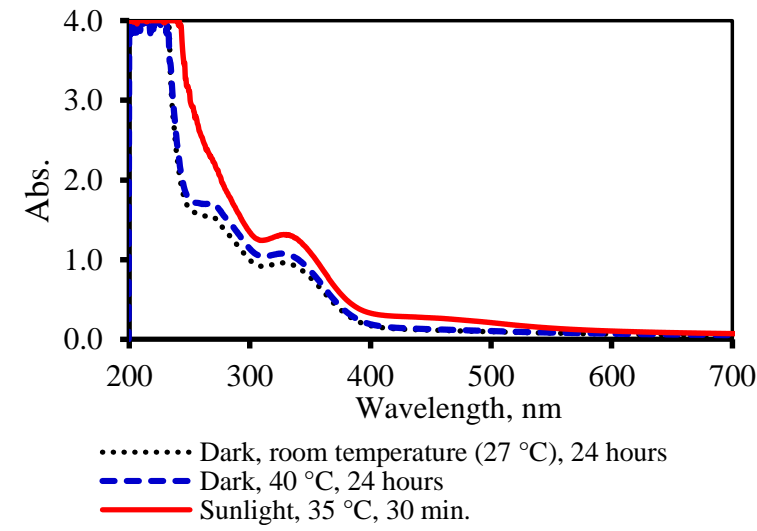

Fig. 1: UV-Vis Spectral Analysis of Different Suspension Samples. 


\subsection{Effects of reaction conditions on AgNPs synthesis}
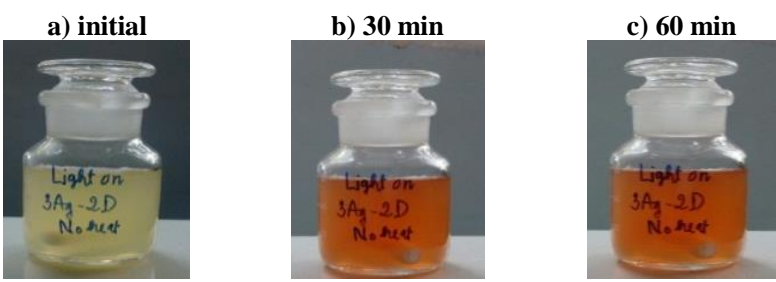

d) $90 \mathrm{~min}$
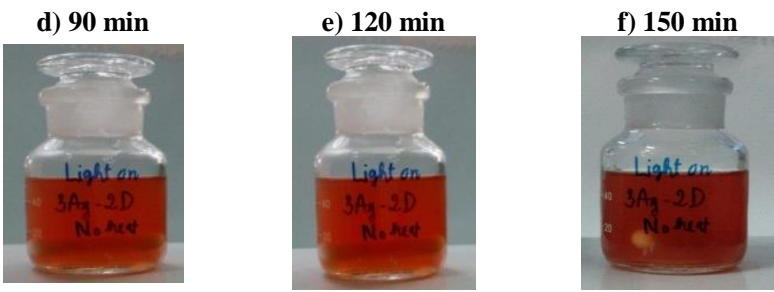

h) $180 \mathrm{~min}$

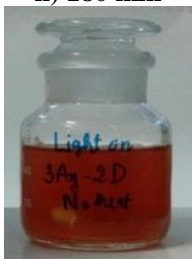

Fig. 2: By-Time Colour of AgNPs Solution (V=50 mL; 3.0Ag/2.0Ext; $\mathrm{T}$ $=35^{\circ} \mathrm{C}$; Sunlight; $\mathrm{V}_{\text {stir }}=300 \mathrm{Rpm} ; \mathrm{C}_{\mathrm{ag}+}=1.0 \mathrm{mM}$ ).

A) Effect of Synthesis Duration $\left(3.0 \mathrm{Ag} / 2.0 \mathrm{Ext} ; \mathrm{T}=35{ }^{\circ} \mathrm{C}\right.$; $\mathrm{V}_{\text {stir }}=300$ $\mathrm{Rpm} ; \mathrm{C}_{\mathrm{ag}+}=1 \mathrm{mM}$ )

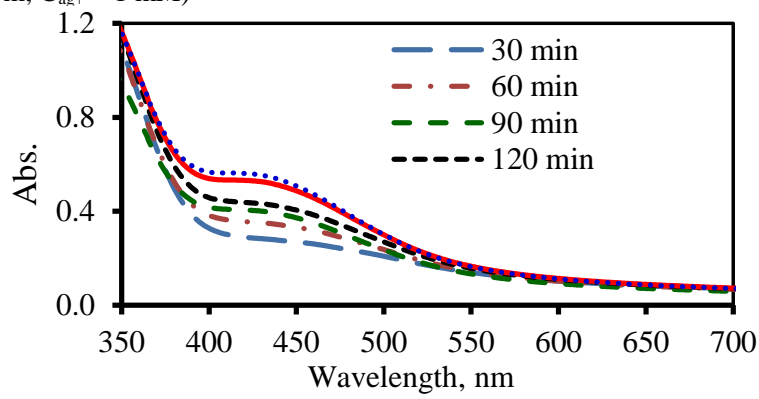

B) Effect of Volume Ratio of $\mathrm{AgNO}_{3}$ Solution/F.J. Extract ( $\mathrm{T}=150 \mathrm{Min}$; $\mathrm{T}=35^{\circ} \mathrm{C} ; \mathrm{V}_{\text {stir }}=300 \mathrm{Rpm} ; \mathrm{C}_{\mathrm{ag}+}=1 \mathrm{mM}$ )

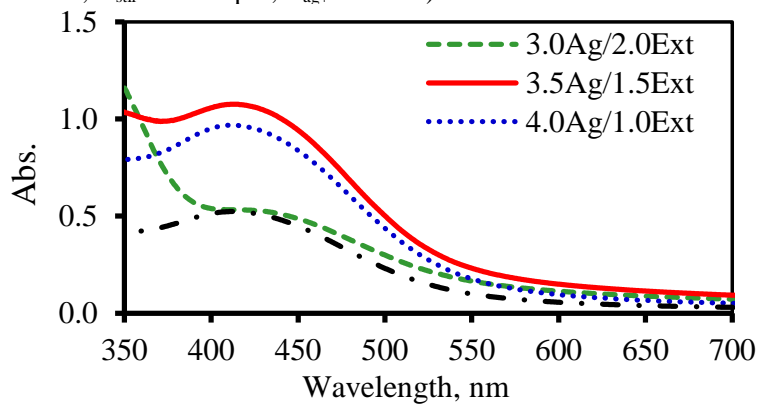

C) Effect of Stirring Rate $\left(\mathrm{T}=150 \mathrm{Min} ; 3.5 \mathrm{Ag} / 1.5 \mathrm{Ext} ; \mathrm{T}=35^{\circ} \mathrm{C} ; \mathrm{C}_{\mathrm{ag}+}=1\right.$ $\mathrm{mM})$

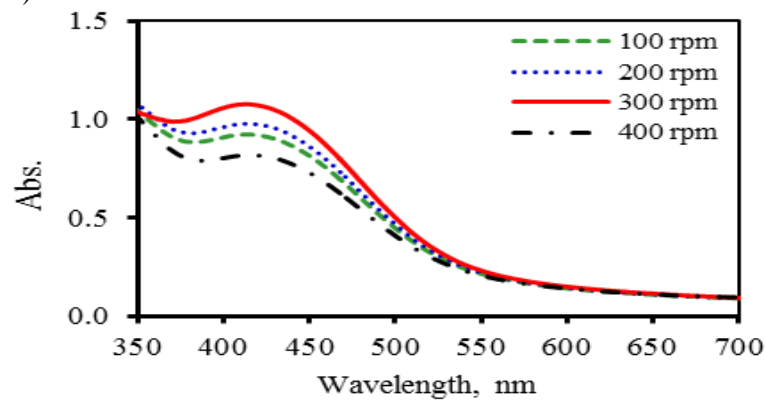

D) Effect of $\mathrm{AgNO}_{3}$ Concentration ( $\mathrm{T}=150 \mathrm{Min} ; 3.5 \mathrm{Ag} / 1.5 \mathrm{Ext}$; $\mathrm{T}=35$ ${ }^{\circ} \mathrm{C} ; \mathrm{V}_{\text {stir }}=300 \mathrm{Rpm}$ )

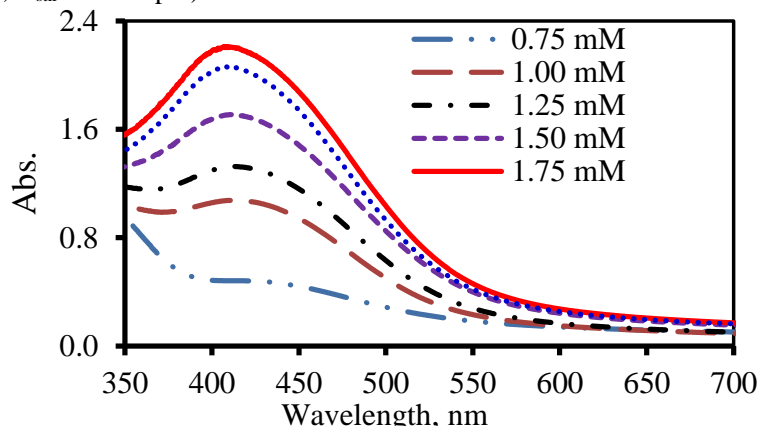

E) Effect of the Synthesis Temperature ( $\mathrm{T}=150 \mathrm{Min}$; 3.5Ag/1.5Ext; $\mathrm{V}_{\text {stir }}$ $=300 \mathrm{Rpm} ; \mathrm{C}_{\mathrm{ag}+}=1.75 \mathrm{mM}$ )

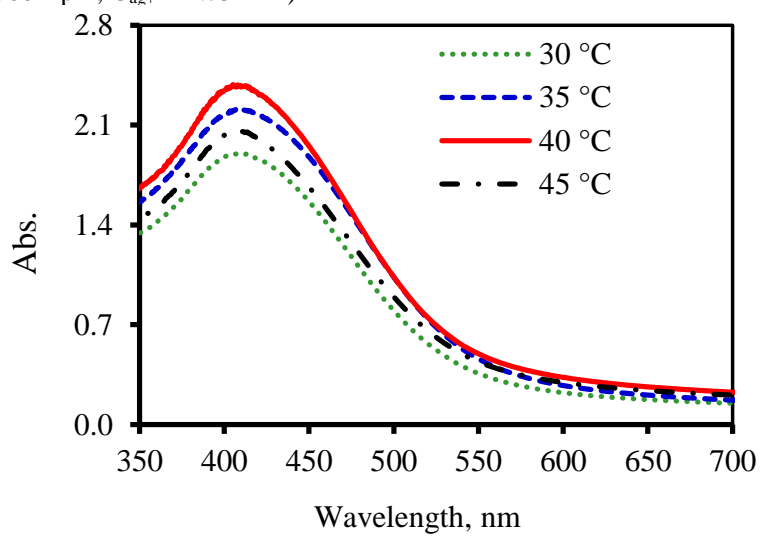

Fig. 3: UV-Vis Spectral Analysis of AgNPs Suspension Samples Synthesized Under Sunlight.

The absorbance peak was broaden indicating high conversion of silver ions to metallic silver nanoparticles at this duration at the early stage (after initial 30 minutes) as shown in Fig. 2 and 3a. When the synthesis time increased, the colour of the reaction mixture changed from yellow to dark brown (Fig.2). Prolonging the reaction time up to 150 minutes led to outstanding enhancement in the plasmon intensity, indicating that large amounts of silver ions were reduced and used for formation of AgNPs. In the reaction duration of up to $180 \mathrm{~min}$, the formed silver nanoparticles just increased slightly, which could be attributed to some aggregation of formed AgNPs. Therefore, 150 minutes were chosen as the optimal reduction time for AgNPs synthesis using F.J. Extract as a combined reducing and stabilizing agent.

The formation of AgNPs reached highest performance with the volume ratio of $\mathrm{AgNO}_{3}$ solution/F.J. Extract at 3.5/1.5 (seen in Fig.3b). With high extract concentrations, the components in the extract had effectively reduced the $\mathrm{Ag}^{+}$ions to $\mathrm{Ag}^{\mathrm{O}}$ and provided enough capping agent for the stabilization of the synthesized nanoparticles through steric hindrance preventing their aggregation [29]. These results were good agreement with those obtained by Subramanian et al. [30].

Fig. 3 c showed when the stirring rate increased from 100 to 300 $\mathrm{rpm}$, the formation of the AgNPs increased. However, while the stirring rate continuously rose up to $400 \mathrm{rpm}$, this formation decreased sharply. The strongly stirring power resulted in effective formation of nanoparticles because high rates of heat and mass transfer were essential in the process, especially on larger scale. Because of the increase in nanostructure concentration, stronger mixing was essential to provide uniform heat and mass transfer [31]. However, when the stirring rate was too high, it could break the AgNPs structure, leading to reducing the efficiency of the process. So, the stirring rate of $300 \mathrm{rpm}$ was consistent for the synthesis process. The effect of $\mathrm{AgNO}_{3}$ concentration on AgNPs formation was also investigated. In Fig.3d, the content of AgNPs increased as raising the initial $\mathrm{Ag}^{+}$concentrations from 0.75 to $1.75 \mathrm{mM}$. However, AgNPs formation decreased in the case of continuously increasing $\mathrm{AgNO}_{3}$ concentration up to $2 \mathrm{mM}$. At low 
concentration, nanoparticles have appeared no more, while nanoparticles have been formed at a higher concentration [32]. However, when silver concentrations were too high, silver nanoparticles agglomerated together reducing the efficiency of the process.

Synthesis of silver nanoparticles was performed at different temperatures in the range of 30 to $45{ }^{\circ} \mathrm{C}$. The results in Figure $3 \mathrm{e}$ showed that the efficiency of silver nanoparticles synthesis was highest at $40^{\circ} \mathrm{C}$.

The suitable conditions for the synthesis of AgNPs using F.J. Extract were determined: the presence of sunlight illumination, $\mathrm{Ag}$ $\mathrm{NO}_{3}$ concentration of $1.75 \mathrm{mM}$, the volume ratio of $\mathrm{AgNO}_{3}$ solution/F.J. Extract of 3.5/1.5, the stirring rate of $300 \mathrm{rpm}$, the synthesis time of 150 minutes and the temperature of $40{ }^{\circ} \mathrm{C}$.

\subsection{The characteristics of synthesized AgNPs}

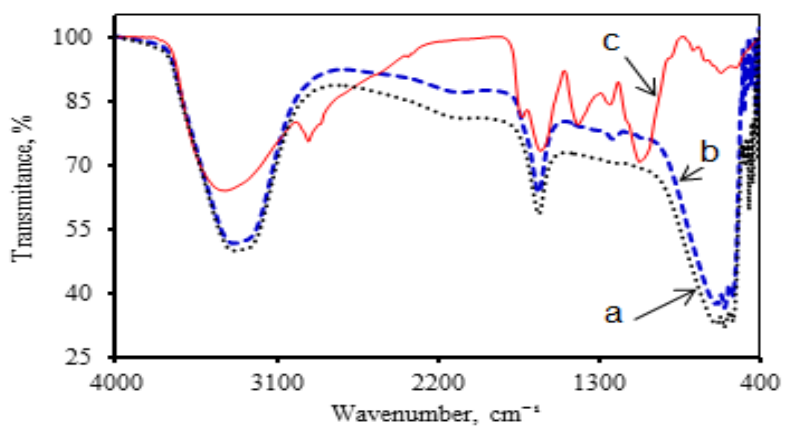

Fig. 4: FT-IR Spectra of F.J. Extract (A), AgNPs Solution (B) and AgNPs Powders (C) Synthesized at the Suitable Conditions.

FT-IR spectra of pure F.J. Extract, AgNPs solution synthesized using F.J. Extract and AgNPs powder dried at $60^{\circ} \mathrm{C}$ were depicted in Fig.4. In all samples, three main bands could be observed. The broad band appearing at $3450 \mathrm{~cm}^{-1}$ was assigned for $\mathrm{O}-\mathrm{H}$ stretching vibration indicating the presence of hydroxyl groups, suggesting the presence of carboxylic acids (citric-main component and ascorbic acids) in the extract $[33,34]$ that acted as both the reducing and stabilizing agents. Two peaks with high intensity at 1380 and $1630 \mathrm{~cm}^{-1}$ correspond to $\mathrm{C}-\mathrm{N}$ stretch vibrations as well as to the amide bands of components in F.J. extract. The difference was not much on samples of pure F.J. Extract and AgNPs solution.

On the FT-IR spectrum of AgNPs powder, a band centered at $2950 \mathrm{~cm}^{-1}$ was related to the axial stretching of $\mathrm{C}-\mathrm{H}$ bonds, a band centered at $1810 \mathrm{~cm}^{-1}$ was attributed to the axial stretching of $\mathrm{C}=\mathrm{O}$ bonds of the acetamide groups, a band at $1420 \mathrm{~cm}^{-1}$ corresponded to the symmetric angular deformation of $\mathrm{CH}_{3}$, and there was a broad band in the wavenumber range of $1153-897 \mathrm{~cm}^{-1}$ indicating the polysaccharide skeleton, including the vibrations of the glycoside bonds, $\mathrm{C}-\mathrm{O}$ and $\mathrm{C}-\mathrm{O}-\mathrm{C}$ stretching. Compare to pure F.J. Extract, the FT-IR spectrum of AgNPs powder showed the presence of weaker signal in the range of $3000-3500 \mathrm{~cm}^{-1}$ in the synthesized nanoparticles. It indicated the decrease in the amount of $\mathrm{O}-\mathrm{H}$ groups of powder AgNPs sample. The decrease of $-\mathrm{O}-\mathrm{H}$ group can be attributed to its reaction with $\mathrm{Ag}^{+}$ions added to the solution for nanoparticles synthesis. When $\mathrm{Ag}^{+}$ions came in contact with $-\mathrm{O}-\mathrm{H}$ groups, the white colloidal particles of $\mathrm{AgOH}$ were formed and then turned into brown $\mathrm{Ag}$ nanoparticles after exposing the solution to bright sunlight due to surface plasmon resonance effect [35].

Fig.5 showed XRD diffraction pattern of AgNPs synthesized using F.J. Extract at the suitable conditions. It presented the feature crystal of AgNPs at $2 \theta=28.5,33.7,38.1,46.3,64.4$, and $76.8^{\circ}$ with the strongest intensity at $2 \theta=38.1^{\circ}$ [36], indicating that the crystal structure of AgNPs was formed. The unassigned small peaks could be due to the crystallization of bio-organic phase occuring on the nanoparticle surface $[36,37]$. Two small peaks observed at $55.3^{\circ}$ and $57.6^{\circ}$ are attributed to the presence of other organic substances in F.J. Extract. Based on XRD result, the average crystal size of AgNPs at $2 \theta=38.1^{\circ}$ was determined following the Scherrer's equation [38]:

$$
d_{\text {crys }}=\frac{\mathrm{K} \lambda}{\beta \cos (\theta)}
$$

Where $\mathrm{d}_{\text {crys }}$ is the crystallite size; $\mathrm{K}$ is a shape factor of the particle (normally $\mathrm{K}=0.94) ; \lambda$ is the wave length of $\mathrm{X}$-ray radiation $(\lambda=$ $1.5406 \AA$ ); $\beta$ is also known as full-width at half the maximum intensity (FWHM) at peak $2 \theta=38.1^{\circ}$; $\theta$ is Bragg angle. The average crystal size of silver nanoparticles synthesized using the F.J. Extract as a combined reducing and stabilizing agent was determined $15.9 \mathrm{~nm}$.

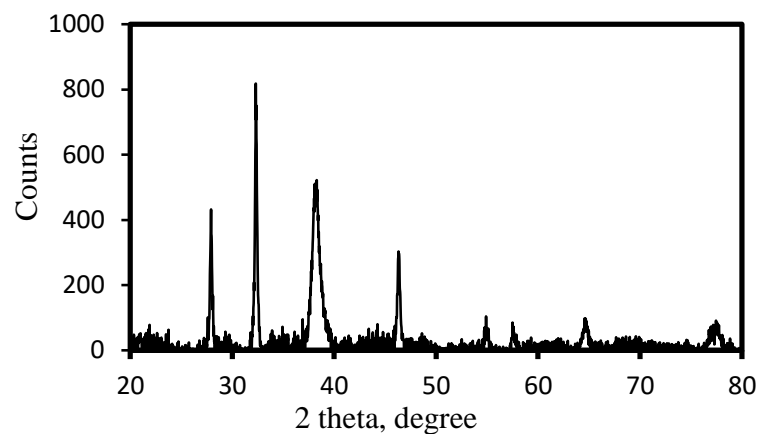

Fig. 5: XRD Diffraction of AgNPs Powder Synthesized at the Suitable Conditions and Dried at $60{ }^{\circ} \mathrm{C}$.

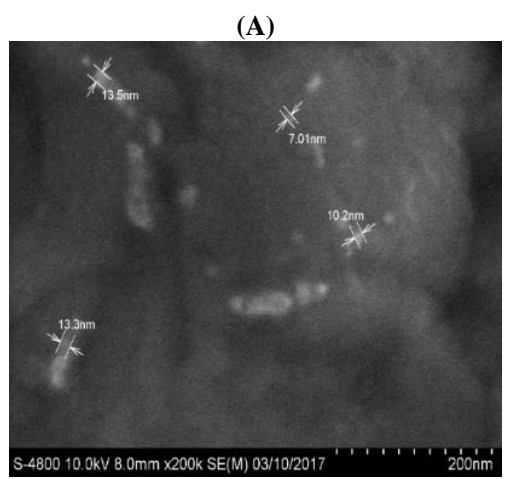

(B)

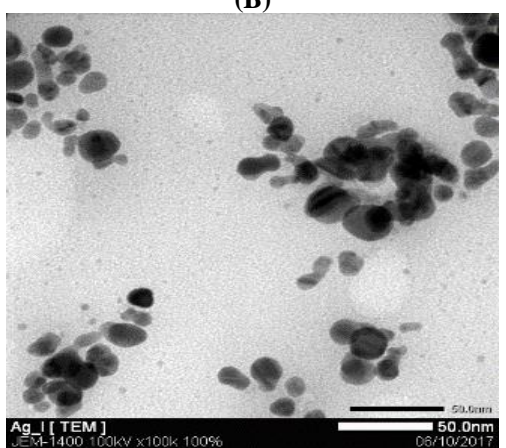

Fig. 6: SEM (A) and TEM (B) Images of AgNPs Synthesized at the Suitable Conditions.

The SEM and TEM images show that the synthesized AgNPs were nanoparticles with the size range of $4-25 \mathrm{~nm}$ (shown in Fig.6). This was consistent with the obtained XRD result.

\subsection{Antibacterial activity of AgNPs}

Fig.7 showed the inhibition zones of the synthesised AgNPs against the two bacterial strains. The zone of inhibition exhibited at each experiment was relatively small and similar. The zones of clearance observed against E. coli and B. subtilis were determined 23.0 and $16.3 \mathrm{~mm}$, respectively. Synthesized AgNPs using of F.J. Extract as a reducing agent against E. coli was much higher than other studies such as Pomegranate fruit seeds $(2.2 \mathrm{~mm})$ [39], Nico- 
tiana tobaccum leaf $(4.0 \mathrm{~mm})$ [40], lemon extract $(3.0 \mathrm{~mm})$ [41] and Neem leaves $(6.0 \mathrm{~mm})$ [42] as reducing and stabilizing agents. The potent antibacterial properties of AgNPs may be attributed to the released $\mathrm{Ag}$ ions, which could have interaction with microorganisms by means of their attaching to the surface of the cell membranes of bacteria and penetrating into the bacterial cells. In the bacterial cells, AgNPs could interact with sulfur- and phosphorus-containing compounds like DNA of bacterial to give rise to the deadly impairment of them [43].
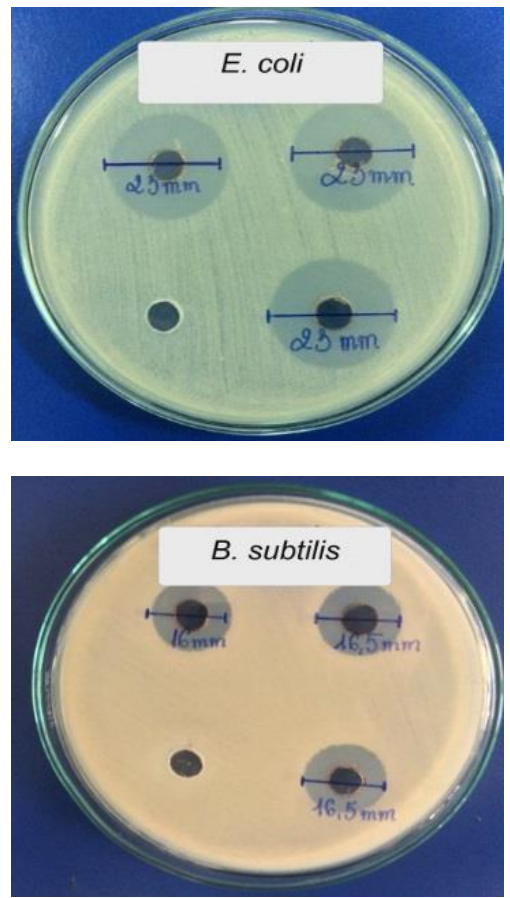

Fig. 7: The Diameter of the Zone Observed Against E. Coli. and B. Subtilis of AgNPs Sample Synthesized at the Suitable Conditions.

\section{Conclusion}

AgNPs were synthesized successfully using Fortunella Japonica extract combined with sunlight illumination. The results showed that the AgNPs formation was strongly dependent on the parameters of the synthesis process such as the time, the volume ratio of $\mathrm{AgNO}_{3}$ solution/F.J. Extract, the stirring rate, the concentration of $\mathrm{AgNO}_{3}$ solution and the temperature. The most suitable conditions for the AgNPs synthesis were proposed. The physico-chemical characteristics indicated that by this biosynthesis the obtained AgNPs were spherical in shape with an average size of $15.9 \mathrm{~nm}$. The synthesized silver nanoparticles showed high antibacterial activity against $\mathrm{E}$. coli and $\mathrm{B}$. subtilis with the zones of clearance being $16.3-23.0 \mathrm{~mm}$.

The reduction accomplished principally due to the combination of the different components of Fortunella Japonica extract and sunlight illumination played the pivotal role in AgNPs formation. The use of Fortunella Japonica extract as a combined reducing and stabilizing agent is one of the most efficient and promising methods in the preparation of AgNPs. It is a green, high yield, fast and low cost approach.

\section{Acknowledgement}

This research is funded by The Incubator for Young Science and Technology Program organized by HCM City Department of Science and Technology and HCM City Youth Union in 2018.

\section{References}

[1] Chaloupka K, Malam Y \& Seifalian AM (2010), Nanosilver as a new generation of nanoproduct in biomedical applications. Trends in biotechnology 28,

https://doi.org/10.1016/j.tibtech.2010.07.006

$580-588$

[2] Prow TW, Grice JE, Lin LL, Faye R, Butler M, Becker W, Wurm EM, Yoong C, Robertson TA \& Soyer HP (2011), Nanoparticles and microparticles for skin drug delivery. Advanced drug delivery reviews 63, 470-491. https://doi.org/10.1016/j.addr.2011.01.012.

[3] Dankovich TA \& Gray DG (2011), Bactericidal paper impregnated with silver nanoparticles for point-of-use water treatment. Environmental science and technology 45, 1992-1998. https://doi.org/10.1021/es103302t.

[4] Nair R, Varghese SH, Nair BG, Maekawa T, Yoshida Y \& Kumar DS (2010), Nanoparticulate material delivery to plants. Plant science 179, 154-163. https://doi.org/10.1016/j.plantsci.2010.04.012.

[5] Fayaz AM, Balaji K, Girilal M, Yadav R, Kalaichelvan PT \& Venketesan R (2010), Biogenic synthesis of silver nanoparticles and their synergistic effect with antibiotics: a study against grampositive and gram-negative bacteria. Nanomedicine: nanotechnology, biology and medicine 6, 103-109. https://doi.org/10.1016/j.nano.2009.04.006.

[6] Wang F, Zeng X, Yao Y, Sun R, Xu J \& Wong C-P (2016), Silver nanoparticle-deposited boron nitride nanosheets as fillers for polymeric composites with high thermal conductivity. Scientific reports 6, 1-9.

[7] Khan Z, Al-Thabaiti SA, Obaid AY \& Al-Youbi A (2011), Preparation and characterization of silver nanoparticles by chemical reduction method. Colloids and surfaces B: Biointerfaces 82, 513-517. https://doi.org/10.1016/j.colsurfb.2010.10.008.

[8] Chen P, Song L, Liu Y \& Fang Y-e (2007), Synthesis of silver nanoparticles by $\gamma$-ray irradiation in acetic water solution containing chitosan. Radiation physics and chemistry 76, 1165-1168. https://doi.org/10.1016/j.radphyschem.2006.11.012.

[9] Zhang W, Qiao X \& Chen J (2006), Synthesis and characterization of silver nanoparticles in AOT microemulsion system. Chemical physics 330 ,

495-500. https://doi.org/10.1016/j.chemphys.2006.09.029.

[10] Reicha FM, Sarhan A, Abdel-Hamid MI \& El-Sherbiny IM (2012), Preparation of silver nanoparticles in the presence of chitosan by electrochemical method. Carbohydrate polymers 89, 236-244. https://doi.org/10.1016/j.carbpol.2012.03.002.

[11] Abid J-P, Wark A, Brevet P-F \& Girault H (2002), Preparation of silver nanoparticles in solution from a silver salt by laser irradiation. $\begin{array}{lll}\text { Chemical communications } & 792-793 .\end{array}$ https://doi.org/10.1039/b200272h.

[12] Yang J \& Pan J (2012), Hydrothermal synthesis of silver nanoparticles by sodium alginate and their applications in surface-enhanced Raman scattering and catalysis. Acta materialia 60, 4753-4758. https://doi.org/10.1016/j.actamat.2012.05.037.

[13] Srikar SK, Giri DD, Pal DB, Mishra PK \& Upadhyay SN (2016), Green synthesis of silver nanoparticles: a review. Green and sustainable chemistry 6, 34-56. https://doi.org/10.4236/gsc.2016.61004

[14] Alarcon EI, Udekwu K, Skog M, Pacioni NL, Stamplecoskie KG, González-Béjar M, Polisetti N, Wickham A, Richter-Dahlfors A \& Griffith M (2012), The biocompatibility and antibacterial properties of collagen-stabilized, photochemically prepared silver nanoparticles. Biomaterials $\quad 33, \quad 4947-4956$ https://doi.org/10.1016/j.biomaterials.2012.03.033.

[15] Sharma VK, Yngard RA \& Lin Y (2009), Silver nanoparticles: green synthesis and their antimicrobial activities. Advances in colloid and interface science 145, 83-96. https://doi.org/10.1016/j.cis.2008.09.002.

[16] Song JY \& Kim BS (2009), Rapid biological synthesis of silver nanoparticles using plant leaf extracts. Bioprocess and biosystems engineering 32, 79-84. https://doi.org/10.1007/s00449-008-0224-6.

[17] Huang H \& Yang X (2004), Synthesis of polysaccharide-stabilized gold and silver nanoparticles: a green method. Carbohydrate research 339, 2627-2631. https://doi.org/10.1016/j.carres.2004.08.005

[18] Bar H, Bhui DK, Sahoo GP, Sarkar P, Pyne S \& Misra A (2009), Green synthesis of silver nanoparticles using seed extract of Jatropha curcas. Colloids and surfaces A: physicochemical and engineering aspects $348, \quad 212-216$ https://doi.org/10.1016/j.colsurfa.2009.07.021.

[19] Narayanan KB \& Sakthivel N (2008), Coriander leaf mediated biosynthesis of gold nanoparticles. Materials letters 62, 4588-4590. https://doi.org/10.1016/j.matlet.2008.08.044.

[20] Sathishkumar M, Sneha K, Won S, Cho C-W, Kim S \& Yun Y-S (2009), Cinnamon zeylanicum bark extract and powder mediated green synthesis of nano-crystalline silver particles and its bactericidal activity. Colloids and surfaces B: Biointerfaces 73, 332-338. https://doi.org/10.1016/j.colsurfb.2009.06.005. 
[21] Daisy P \& Saipriya K (2012), Biochemical analysis of Cassia fistula aqueous extract and phytochemically synthesized gold nanoparticles as hypoglycemic treatment for diabetes mellitus. International journal of nanomedicine 7, 1189-1202. https://doi.org/10.2147/IJN.S26650.

[22] Ankamwar B, Damle C, Ahmad A \& Sastry M (2005), Biosynthesis of gold and silver nanoparticles using Emblica officinalis fruit extract, their phase transfer and transmetallation in an organic solution. Journal of nanoscience and nanotechnology 5, 1665-1671. https://doi.org/10.1166/jnn.2005.184.

[23] Schirra M, Palma A, D’Aquino S, Angioni A, Minello EV, Melis M \& Cabras P (2007), Influence of postharvest hot water treatment on nutritional and functional properties of kumquat (Fortunella japonica Lour. Swingle Cv. Ovale) fruit. Journal of agricultural and food chemistry 56, 455-460. https://doi.org/10.1021/jf0714160.

[24] Jayaprakasha G, Murthy KC, Etlinger M, Mantur SM \& Patil BS (2012), Radical scavenging capacities and inhibition of human prostate $(\mathrm{LNCaP})$ cell proliferation by Fortunella margarita. Food chemistry 131 ,

184-191. https://doi.org/10.1016/j.foodchem.2011.08.058.

[25] Tan S, Li M, Ding X, Fan S, Guo L, Gu M, Zhang Y, Feng L, Jiang D \& Li Y (2014), Effects of Fortunella margarita fruit extract on metabolic disorders in high-fat diet-induced obese C57BL/6 mice. PLoS One 9, e93510. https://doi.org/10.1371/journal.pone.0093510.

[26] Wang Y-W, Zeng W-C, Xu P-Y, Lan Y-J, Zhu R-X, Zhong K, Huang Y-N \& Gao H (2012), Chemical composition and antimicrobial activity of the essential oil of Kumquat (Fortunella crassifolia Swingle) Peel. International journal of molecular sciences 13, 3382-3393. https://doi.org/10.3390/ijms13033382.

[27] Arora DS \& Kaur J (1999), Antimicrobial activity of spices. International journal of antimicrobial agents 12, 257-262. https://doi.org/10.1016/S0924-8579(99)00074-6.

[28] Kumar V, Gundampati RK, Singh DK, Bano D, Jagannadham MV \& Hasan SH (2016), Photoinduced green synthesis of silver nanoparticles with highly effective antibacterial and hydrogen peroxide sensing properties. Journal of Photochemistry and Photobiology B: Biology 162, 374-385. https://doi.org/10.1016/j.jphotobiol.2016.06.037.

[29] Rastogi L \& Arunachalam J (2013), Green synthesis route for the size controlled synthesis of biocompatible gold nanoparticles using aqueous extract of garlic (Allium sativum). Adv. Mater. Lett 4, 548-555. https://doi.org/10.5185/amlett.2012.11456.

[30] Subramanian R, Subbramaniyan P \& Raj V (2013), Antioxidant activity of the stem bark of Shorea roxburghii and its silver reducing power. SpringerPlus 2, 1-11. https://doi.org/10.1186/21931801-2-28.

[31] Hemmati S \& Barkey DP (2017), Parametric Study, Sensitivity Analysis, and Optimization of Polyol Synthesis of Silver Nanowires. ECS Journal of Solid State Science and Technology 6, 132137. https://doi.org/10.1149/2.0141704jss.

[32] Moosa AA, Ridha AM \& Al-Kaser M (2015), Process parameters for green synthesis of silver nanoparticles using leaves extract of aloe vera plant. International journal of multidisciplinary and current research 3, 966-975.

[33] Benavente-García O, Castillo J, Marin FR, Ortuño A \& Del Río JA (1997), Uses and properties of citrus flavonoids. Journal of agricultural and food chemistry 45, 4505-4515. https://doi.org/10.1021/jf970373s.

[34] Sigmann SB \& Wheeler DE (2004), Quantitative determination of citric and ascorbic acid in powdered drink mixes: A high school or general chemistry experiment. Journal of chemical education 81, 1479. https://doi.org/10.1021/ed081p1479.

[35] Wu T, Liu S, Luo Y, Lu W, Wang L \& Sun X (2011), Surface plasmon resonance-induced visible light photocatalytic reduction of graphene oxide: using $\mathrm{Ag}$ nanoparticles as a plasmonic photocatalyst. Nanoscale 3, 2142-2144. https://doi.org/10.1039/c1nr10128e.

[36] Jha AK \& Prasad K (2011), Green fruit of chili (Capsicum annum L.) synthesizes nano silver. Digest Journal of nanomaterials and biostructures 6, 1717-1723.

[37] Ahmad N \& Sharma S (2012), Green synthesis of silver nanoparticles using extracts of Ananas comosus. Green and Sustainable Chemistry 2, 141-147. https://doi.org/10.4236/gsc.2012.24020.

[38] Patterson AL (1939), The scherrer formula for X-ray particle size determination. Physical review 56(10), 978-982. https://doi.org/10.1103/PhysRev.56.978.

[39] Chauhan S, Upadhyay MK, Rishi N \& Rishi S (2011), Phytofabrication of silver nanoparticles using pomegranate fruit seeds. International journal of Nanomaterials and Biostructures 1, 17-21.

[40] Prasad KS, Pathak D, Patel A, Dalwadi P, Prasad R, Patel P \& Selvaraj K (2011), Biogenic synthesis of silver nanoparticles using Ni- cotiana tobaccum leaf extract and study of their antibacterial effect. African Journal of Biotechnology 10, 8122-8130. https://doi.org/10.5897/AJB11.394.

[41] Link MP, Goorin AM, Miser AW, Green AA, Pratt CB, Belasco JB, Pritchard J, Malpas JS, Baker AR \& Kirkpatrick JA (1986), The effect of adjuvant chemotherapy on relapse-free survival in patients with osteosarcoma of the extremity. New England Journal of Medicine $314, \quad 1600-1606$. https://doi.org/10.1056/NEJM198606193142502.

[42] Verma A \& Mehata MS (2016), Controllable synthesis of silver nanoparticles using Neem leaves and their antimicrobial activity. Journal of radiation Research and applied sciences 9, 109-115. https://doi.org/10.1016/j.jrras.2015.11.001.

[43] Morones JR, Elechiguerra JL, Camacho A, Holt K, Kouri JB, Ramírez JT \& Yacaman MJ (2005), The bactericidal effect of silver nanoparticles. Nanotechnology 16, 2346-2353. https://doi.org/10.1088/0957-4484/16/10/059. 